Post Print

This is the peer-reviewed version of the following article

Jean-Yves Wach, Simone Bonazzi and Karl Gademann Antimicrobial Surfaces through Natural Product Hybrids Angew. Chem. Int. Ed. 2008, 47, 7123-7126.

DOI: 10.1002/anie.200801570

This post print was deposited at http://infoscience.epfl.ch In compliance with the directive of the Swiss National Science Foundation 


\title{
Antimicrobial Surfaces Through Natural Product Hybrids[**]
}

\author{
Jean-Yves Wach, Simone Bonazzi, and Karl Gademann*
}

Infections after treatments in hospitals and nursing homes (nosocomial infections) pose a significant threat for patients, ${ }^{[1]}$ which is further accentuated by the increase of resistant pathogens. ${ }^{[2]}$ High infection rates are in particular observed related to implants, catheters, and stents ${ }^{[3]}-e$.g. those for urinary catheters mounting up to $30 \%$ per week. The encapsulation of implants by surrounding tissue adds further complications, as antibiotics are hardly reaching their site of action resulting in up to 1000 times decreased efficiency. ${ }^{[2, \mathrm{~d}, \mathrm{~d}, \mathrm{e}, 5]}$ As a direct consequence, the replacement of implants remains often the therapy of choice, implicating large costs and suffering for the patients and their families. An attractive approach for preventing such nosocomial infections resides in the attachment of antibiotics to biomaterials. ${ }^{[6]}$ In this communication, we report the design, the preparation and biological evaluation of a natural product hybrid for the generation of antimicrobial surfaces. ${ }^{[7]}$ Natural product hybrids are compounds that combine biologically active fragments of two different natural products, with the goal of synergistically merging different modes of action. ${ }^{[8]}$ For example, cytotoxic derivatives of CC-1065 were hybridized with DNA-binding natural products ${ }^{[9 a, b]}$ or carbohydrates $^{[9 c]}$ resulting in highly selective and potent compounds. We recently reported that derivatives of the cyanobacterial siderophore anachelin ${ }^{[10]}$ are able to strongly bind to metal oxide surfaces. ${ }^{[11]}$ Protein-resistant surfaces of $\mathrm{TiO}_{2}$ were thus prepared by dip-and-rinse procedures in solutions of the pegylated anachelin chromophore $1 .^{[11]} \mathrm{We}$ thus asked the question whether these strong surface binding properties of

[*] Prof. Dr. K. Gademann,

J.-Y. Wach, M. Sc.

S. Bonazzi, M. Sc.

Chemical Synthesis Laboratory

Swiss Federal Institute of Technology (EPFL)

$\mathrm{CH}-1015$ Lausanne/Switzerland

Fax: (+)41216939700

E-mail: karl.gademann@epfl.ch

Homepage: http://lsync.epfl.ch

[**] We thank the Swiss National Science Foundation for support (Projektnr. 200021-115918/1). This work is part of the planned dissertation of S. B. at ETH Zürich. We thank D ${ }^{n}$ alisova for the preparation of the Ti chips.

Supporting information for this article is available on the WWW under http://www.angewandte.org or from the author. anachelin can be hybridized with an antibiotic natural product. As a target molecule, we chose hybrid 2, in which the anachelin chromophore is linked via a poly-ethyleneglycol (PEG) linker to the clinically used antibiotic vancomycin. Each of these fragments should contribute a desired function in hybrid 2: The anachelin chromophore should enable the immobilization of the hybrid on the surface; vancomycin should inhibit the growth of bacteria, and the long PEG-3000 linker should allow for protein and cell resistance of the modified surfaces, as well as for optimal presentation of the antibiotic on the surface.
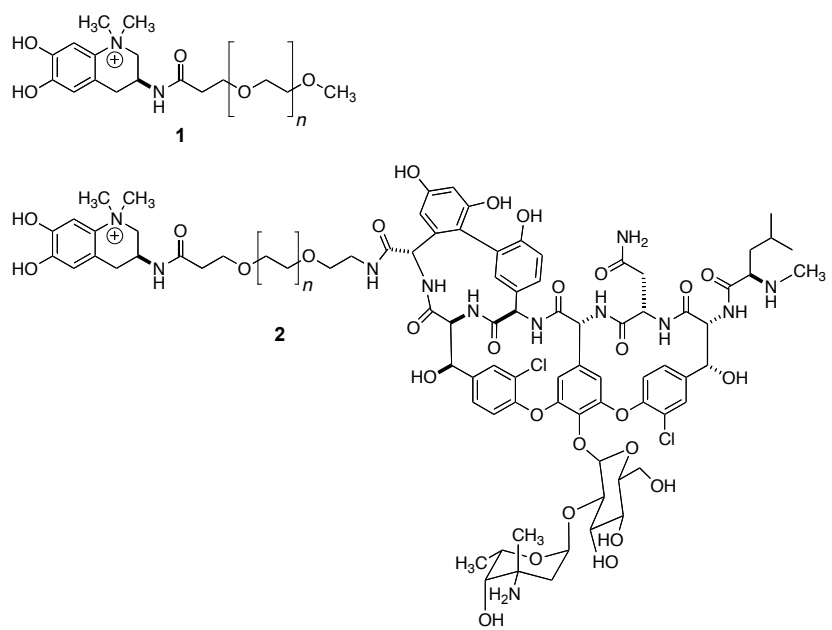

The synthesis of target compound $\mathbf{2}$ commenced with the preparation of the anachelin chromophore, which can be prepared starting from Boc-L-DOPA (Scheme 1). ${ }^{[10 \mathrm{c}, \mathrm{d}, \mathrm{g}]}$ Deprotection of the Boc-group ( $\mathrm{HCl}$ in dioxane) and subsequent coupling to the bifunctional Fmoc-NH-PEG-succinidyl ester resulted in the pegylated anachelin chromophore derivative 4. Mild deprotection of the Fmoc group by piperidine gave the terminal amine, which was coupled to vancomycin by using HATU according to a modified literature procedure ${ }^{[12]}$ and the resulting hybrid 2 was finally purified by size-exclusion-chromatography.

We investigated at first, whether the modification of vancomyicn to the hybrid 2 had an impact on biological activity. Both vancomycin and the hybrid $\mathbf{2}$ were tested in disk diffusion experiments on Bacillus subtillis ATCC 6633, and the hybrid 2 retained the antimicrobial activity of the parent compound, albeit reduced roughly by a factor of 2 . This can be explained by the higher molecular weight and the resulting lower diffusion rate of hybrid 2. 


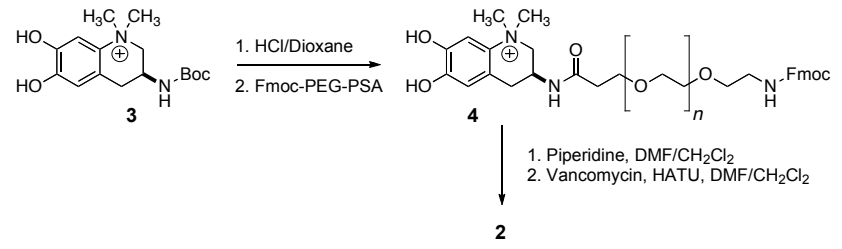

Scheme 1. Preparation of hybrid 2.

We then investigated the biological properties of $\mathrm{TiO}_{2}$ after surface modification using the hybrid $\mathbf{2}$. Titanium is frequently utilized in implants due its favorable properties as a biocompatible material. We functionalized $\mathrm{TiO}_{2}$ surfaces by using a simple procedure that has been previouslt developed for the anachelin chromophore. ${ }^{[1]} \mathrm{TiO}_{2}$ chips were incubated in a solution of the hybrid 2 in MOPS buffer for $4 \mathrm{~h}$, and subsequently washed with HEPES buffer. This dip-and-rinse procedure allowed not only for the successful functionalization of $\mathrm{TiO}_{2}$, but also of glass slides.

The resulting functionalized $\mathrm{TiO}_{2}$ surfaces were then evaluated for their biological activity and antimicrobial action on bacteria. We used the live/dead kit, ${ }^{[13]}$ that allowed for differentiation of live and dead cells by fluorescence microscopy. Whereas living cells are stained green, the DNA in dead cells is labeled by a red fluorescent dye. As a model organism, we chose Bacillus subtilis ATCC $6633,{ }^{[14]}$ which is susceptible to vancomycin. ${ }^{[15]}$ As control, we incubated non-coated $\mathrm{TiO}_{2}$ chips in bacterial suspensions, and live/dead staining detected viable cells (Figure 1a). As a positive control, an untreated $\mathrm{TiO}_{2}$ surface was incubated in B. subtilis in the presence of dissolved vancomycin, and only dead cells were detected by fluorescence microscopy after staining (Figure 1b). ${ }^{[16]}$

After these positive and negative controls, we incubated functionalized surfaces in suspensions of $B$. subtilis. After incubation for $6 \mathrm{~h}$, the viability of cells was examined by live/dead staining (Figure 1c). Only dead cells could be detected by this method, and the biological properties of both immobilized (Figure 1c) and dissolved vancomycin (Figure 1B) were identical. In order to test whether immobilized hybrid $\mathbf{2}$ is responsible for the antimicrobial activity, we evaluated the dipand-rinse solution, the rinsing solution, as well as a blank incubation solution (medium, no bacteria), for antibacterial activity, all of them were not active. These combined experiments demonstrate that the immobilized hybrid $\mathbf{2}$ is the active principle (see also leaching experiments discussed below). We investigated next, whether the dead cells remain attached to the functionalized surface, or whether they can be removed by rinsing. The natural product hybrid surface was thus rinsed by buffer after incubation, and the number of cells was visualized by staining and fluorescence microscopy. Interestingly, the number of dead cells is drastically reduced (Figure 1d), and only few dead cells remain on the surface. These experiments are important as they demonstrate that the PEG linker displays cell resistant properties by suppressing the attachment of bacteria on dead cells or cell material. We investigated next whether the hybrid 2, and in particular the vancomycin fragment, is responsible for biological activity. ${ }^{[17]} \mathrm{We}$ adsorbed the PEGanachelin chromohore derivative $\mathbf{1}$ on $\mathrm{TiO}_{2}$, and incubated the resulting pegylated surfaces in suspensions of $B$. subtilis. Staining and visualization displayed only living cells, and demonstrated that no antimicrobial activity for unfunctionalized PEG derivative 1 was obtained (Figure 1e). Rinsing by buffer again significantly reduced the number of cells (Figure 1f). These experiments thus demonstrate that conjugate $\mathbf{1}$ is capable of generating cell-resistant surfaces, although with no antimicrobial activity. This biological property can only be obtained with natural product hybrid 2. a)

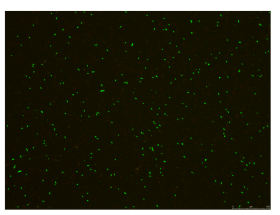

c)

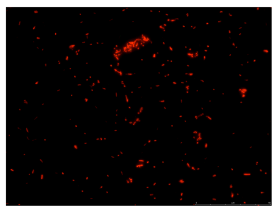

e)

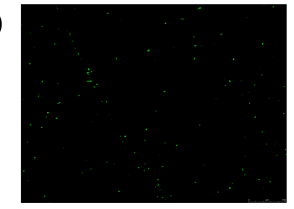

b)

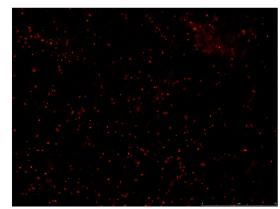

d)

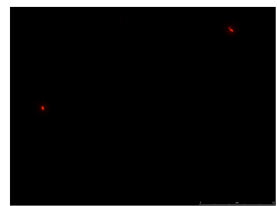

f)

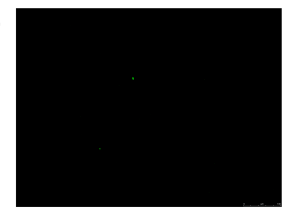

Figure 1. Representative samples of $\mathrm{TiO}_{2}$ surfaces after incubation in suspensions of $B$. subtilis ATCC 6633 (6 h) and subsequent staining with the live/dead $\mathrm{kit}^{[13]}$ visualized using fluorescence microscopy (see also the Supporting Information). a: Untreated $\mathrm{TiO}_{2}$ surfaces; b: Untreated $\mathrm{TiO}_{2}$ surfaces and vancomycin in solution; $\mathbf{c}$ : $\mathrm{TiO}_{2}$ surfaces modified with hybrid 2 ; $\mathbf{d}$ : $\mathrm{TiO}_{2}$ surfaces modified with hybrid 2 after rinsing with PBS buffer; e: $\mathrm{TiO}_{2}$ surface pegylated with $\mathbf{1} ; \mathbf{f}$ : $\mathrm{TiO}_{2}$ surfaces pegylated with 1 after rinsing with PBS buffer.
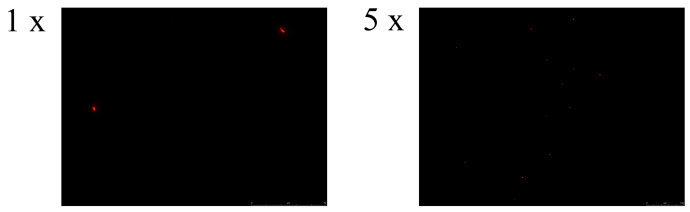

Figure 2. Representative samples of $\mathrm{TiO}_{2}$ surface treated with hybrid 2 after incubation in suspensions of $B$. subtilis and rinsing (left), and five cycles of incubation and rinsing (right), visualized with fluorescence microscopy after live/dead staining. ${ }^{[13]}$

We then investigated, whether the hybrid 2 remains immobilized on the surface upon repeated exposure to buffer or medium. An antimicrobial $\mathrm{TiO}_{2}$ surface coated with hybrid $\mathbf{2}$ was thus incubated in a bacterial suspension for $6 \mathrm{~h}$ and rinsed by buffer, and this process repeated five times. As clearly shown in Figure 2, both the antimicrobial activity and the cell-resistant properties remain present after five cycles. From these experiments, it can be concluded that the binding of hybrid $\mathbf{2}$ on $\mathrm{TiO}_{2}$ surfaces is rather strong. This statement is corroborated by research on similar DOPA peptides by other groups: ${ }^{[18]}$ Messersmith and coworkers measured by AFM measurements the dissociation force of the DOPA- $\mathrm{TiO}_{2}$ bond to be over $800 \mathrm{pN}$, which is one of the strongest measured reversible interactions to date. ${ }^{[18 d]}$ These investigations underline the great potential of catechols, and in particular the anachelin chromophore, for the 
functionalization of surfaces, and thus form the basis of the success of hybrid $\mathbf{2}$.

In this communication, we presented the synthesis, immobilization, and biological evaluation of the natural product hybrid 2 for the generation of antimicrobial surfaces. This compound combines the properties of the respective natural products: The anachelin chromophore allows for a strong binding to $\mathrm{TiO}_{2}$ surfaces, and vancomycin is responsible for the biological activity. In addition, the PEG linker contributes to cell resistance thus suppressing the attachment of dead cells and cell material. The benefits of the surfaces modified by hybrid $\mathbf{2}$ include: (1) Simple preparation through a dip-and-rinse procedure. (2) Strong antimicrobial activity in these model studies against B. subtilis; (3) cell-resistant properties suppressing the attachment of dead cells and cell materials; (4) strong surface attachment through the anachelin chromophore allowing for high activity after several cycles. The benefits of the reported hybrid strategy should be applicable to many other natural products as well. In particular the compatibility of the catechol group to functional groups found in bioactive small molecules (in contrast to commonly used silanes and thiols) could enable use of this method for small molecule microarrays. In addition, the unique properties of natural products could be exploited to control biological processes such as growth, differentiation, and movement on surfaces through such natural product hybrids.

Published online on ((will be filled in by the editorial staff))

Keywords: Antibiotics - Biomaterials - Conjugates - Natural

Products Chemistry - Organic Synthesis

[1] a) P. W. Stone, D. Braccia, E. Larson, American Journal of Infection Control 2005, 33, 501; b) D. Cardo, T. Horan, M. Andrus, M. Dembinski, J. Edwards, G. Peavy, J. Tolson, D. Wagner, American Journal of Infection Control 2004, 32, 470; c) J. P. Burke, N. Engl. J. Med. 2003, 348, 651; d) L. L. Leape, T. A. Brennan, N. Laird, A. G. Lawthers, A. R. Lacolio, B. A. Barnes, L. Hebert, J. P. Newhouse, P. C. Weiler, H. Hiatt, N. Engl. J. Med. 1991, 324, 377.

[2] a) T. F. C. Mah, G. A. O'Toole, Trends Microbiol. 2001, 9, 34; b) P. S. Stewart, J. W. Costerton, Lancet 2001, 358, 135; c) C. Walsh, Nature 2000, 406, 775; d) J. W. Costerton, Z. Lewandowski, D. E. Caldwell, D. R. Korber, H. M. Lappin-Scott, Annu. Rev. Microbiol. 1995, 49, 711; e) J. W. Costerton, P. S. Stewart, E. P. Greenberg, Science 1999, 284, 1318; f) H. S. Gold, R. C. Moellering Jr, $N$. Engl. J. Med. 1996, 335, 1445.

[3] a) B. Foxman, Am. J. Med. 2002, 113, 5S; b) K. L. Garvin, A. D. Hanssen, J. Bone Joint Surg. A 1995, 77, 1576; c) N. Rao, G. L. Soxman, Op. Techn. Orthopaedics 2002, 12, 131; d) S. Saint, C. E. Chenoweth, Infectious Disease Clinics of North America 2003, 17, 411; e) J. W. Warren, Medical Clinics of North America 1991, 75, 481; f) W. Zimmerli, A. Trampuz, P. E. Ochsner, N. Engl. J. Med. 2004, 351, 1701.

[4] L. E. Nicolle, Clinical Infect. Diseases 2008, 46, 251.

[5] J. M. Rodriguez-Martinez, A. Pascual, Rev. Med. Microbiol. 2006, 17,65 .

[6] a) V. Antoci Jr, C. S. Adams, N. J. Hickok, I. M. Shapiro, J. Parvizi, Clinical Orthopaedics and Related Research 2007, 88; b) V. Antoci Jr, S. B. King, B. Jose, J. Parvizi, A. R. Zeiger, E.
Wickstrom, T. A. Freeman, R. J. Composto, P. Ducheyne, I. M. Shapiro, N. J. Hickok, C. S. Adams, Journal of Orthopaedic Research 2007, 25, 858; c) O. P. Edupuganti, V. Antoci Jr, S. B. King, B. Jose, C. S. Adams, J. Parvizi, I. M. Shapiro, A. R. Zeiger, N. J. Hickok, E. Wickstrom, Bioorg. Med. Chem. Lett. 2007, 17, 2692; d) B. Jose, V. Antoci Jr, A. R. Zeiger, E. Wickstrom, N. J. Hickok, Chem. Biol. 2005, 12, 1041.

[7] a) F. Gelman, K. Lewis, A. M. Klibanov, Biotechnol. Lett. 2004, 26, 1695; b) J. Haldar, D. An, L. A. De Cienfuegos, J. Chen, A. M. Klibanov, Proc. Natl. Acad. Sci. U. S. A. 2006, 103, 17667; c) J. Haldar, J. Chen, T. M. Tumpey, L. V. Gubareva, A. M. Klibanov, Biotechnol. Lett. 2008, 30, 475; d) J. Haldar, A. K. Weight, A. M. Klibanov, Nature Prot. 2007, 2, 2412; e) A. M. Klibanov, J. Mater. Chem. 2007, 17, 2479; f) K. Lewis, A. M. Klibanov, Trends Biotechnol. 2005, 23, 343; g) J. Lin, S. K. Murthy, B. D. Olsen, K. K. Gleason, A. M. Klibanov, Biotechnol. Lett. 2003, 25, 1661; h) J. Lin, S. Qiu, K. Lewis, A. M. Klibanov, Biotechnol. Prog. 2002, 18 , 1082; i) J. Lin, S. Qiu, K. Lewis, A. M. Klibanov, Biotechnol. Bioeng. 2003, 83, 168; j) J. Lin, J. C. Tiller, S. B. Lee, K. Lewis, A. M. Klibanov, Biotechnol. Lett. 2002, 24, 801; k) N. M. Milovic, J. Wang, K. Lewis, A. M. Klibanov, Biotechnol. Bioeng. 2005, 90, 715 ; 1) D. Park, J. Wang, A. M. Klibanov, Biotechnol. Prog. 2006, 22,$584 ;$ m) J. C. Tiller, S. B. Lee, K. Lewis, A. M. Klibanov, Biotechnol. Bioeng. 2002, 79, 465; n) J. C. Tiller, C. J. Liao, K. Lewis, A. M. Klibanov, Proc. Natl. Acad. Sci. 2001, 98, 5981.

[8] Uebersichtsartikel: a) K. Gademann, Chimia 2006, 60, 841; b) L. F. Tietze, H. P. Bell, S. Chandrasekhar, Angew. Chem. 2004, 116, 3511; Angew. Chem. Int. Ed. 2003, 42, 3996; c) G. Mehta, V. Singh, Chem. Soc. Rev. 2002, 31, 324.

[9] a) N. L. Fregeau, Y. Wang, R. T. Pon, W. A. Wylie, J. W. Lown, J. Am. Chem. Soc. 1995, 117, 8917-8925; b) Y. Wang, R. Gupta, L. Huang, W. Luo, J. W. Lown, Anti-Cancer Drug Des. 1996, 11, 1534; c) L. F. Tietze, T. Feuerstein, A. Fecher, F. Haunert, O. Panknin, U. Borchers, I. Schuberth, F. Alves, Angew. Chem. 2002, 114, 785-787; Angew. Chem. Int. Ed. 2002, 41, 759-761.

[10] a) H. Beiderbeck, K. Taraz, H. Budzikiewicz, A. E. Walsby, Z. Naturforsch. C 2000, 55, 681; b) Y. Ito, S. Okada, M. Murakami Tetrahedron 2001, 57, 9093; c) K. Gademann, Y. Bethuel, Org. Lett. 2004, 6, 4707; d) K. Gademann, Y. Bethuel, Angew. Chem. 2004, 116, 3389; Angew. Chem., Int. Ed. 2004, 43, 3327; e) Y. Ito, K. Ishida, S. Okada, M. Murakami, Tetrahedron 2004, 60, 9075; f) Y. Bethuel, K. Gademann, J. Org. Chem. 2005, 70, 6258; g) K. Gademann, ChemBioChem 2005, 6, 913.

[11] S. Zürcher, D. Wäckerlin, Y. Bethuel, B. Malisova, M. Textor, S. Tosatti, K. Gademann, J. Am. Chem. Soc. 2006, 128, 1064.

[12] B. Xing, C.-W. Yu, K.-H. Chow, P.-L. Ho, D. Fu, B. Xu, J. Am. Chem. Soc. 2002, 124, 14846.

[13] B. L. Roth, M. Poot, S. T. Yue, P. J. Millard, Appl. Environ. Microbiol 1997, 63, 2421

[14] I. W. Dawes, J. Mandelstam, J. Bacteriol. 1970, 103, 529.

[15] a) J. D. Coonrod, P. J. Leadley, T. C. Eickhoff, J. Infect. Dis. 1971, 123,102 ; b) D. J. Weber, S. M. Saviteer, W. A. Rutala, C. A. Thomann, Antimicrob. Agents Chemother. 1988, 32, 642.

[16] The cells (in Figure 1a) and cell components (in Figure 1b) could largely not be removed by washing from the surface.

[17] The anachelin chromophore was evaluated in a panel of the pathogens, and only weak activity $(32 \mu \mathrm{g} / \mathrm{ml})$ against Moraxella catarrhalis A-894 was found, no activity was found in concentrations up to $64 \mu \mathrm{g} / \mathrm{ml}$ against $S$. aureus und E. faecium: K. Gademann, Y. Bethuel, H. H. Locher, C. Hubschwerlen, J. Org. Chem. 2007, 72, 8361 .

[18] a) J. L. Dalsin, B. H. Hu, B. P. Lee, P. B. Messersmith, J. Am. Chem. Soc. 2003, 125, 4253; b) J. L. Dalsin, P. B. Messersmith, Materials Today 2005, 8, 38; c) X. Fan, L. Lin, J. L. Dalsin, P. B. Messersmith, J. Am. Chem. Soc. 2005, 127, 15843; d) H. Lee, N. F. Scherer, P. B. Messersmith, Proc. Natl. Acad. Sci. U. S. A. 2006, 103, 12999; e) J. H. Waite, M. L. Tanzer, Science 1981, 212, 1038. 
Entry for the Table of Contents (Please choose one layout)

Layout 1:

\section{Natural Product Hybrids}

J.-Y. Wach, S. Bonazzi, K. Gademann* Page - Page

Antimicrobial surfaces through natural product hybrids

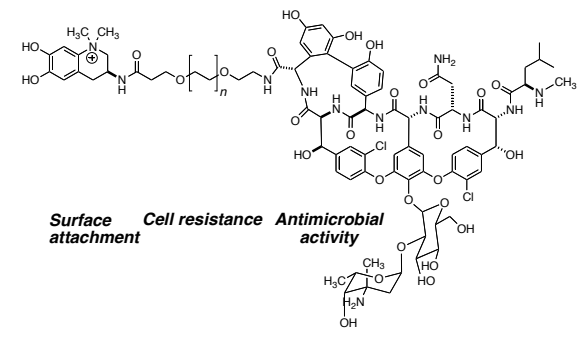

\section{The power of two!}

The natural product hybrid of a siderophore and an antibiotic enables the preparation of antimicrobial and cellresistant surfaces. 